\title{
GEOARQUEOLOGÍA EN PALI AIKE: CUEVA OREJAS DE BURRO 1 (PATAGONIA, ARGENTINA)
}

«every archaeological problem starts as a problem in geoarchaeology»

Renfrew (1976: 2)

\author{
RAMIRO BARBERENA*, ADRIANA BLASI ** y CAROLA CASTIÑEIRA *** \\ RESUMEN
}

En este trabajo se presentan los resultados estratigráficos y geoarqueológicos obtenidos en el sitio Orejas de Burro 1, ubicado en el sector meridional del campo volcánico de Pali Aike (Santa Cruz, Argentina). Se desarrollan discusiones relacionadas con los procesos de formación de los depósitos, la cronología de los conjuntos arqueológicos contenidos en ellos y las implicaciones paleoambientales regionales de ciertos indicadores sedimentológicos. Este caso constituye un primer paso para el desarrollo de un esquema geoarqueológico dirigido a integrar el registro de sitios estratificados en reparos rocosos, en el marco de preguntas sobre biogeografía humana en Patagonia meridional.

PALABRAS CLAVES: geoarqueología, cuevas, Pali Aike.

CAVE GEOARCHAEOLOGY: OREJAS DE BURRO 1 SITE (PALI AIKE, ARGENTINA)

\section{ABSTRACT}

We present stratigraphic and geoarchaeological evidences from the Orejas de Burro 1 archaeological site, located in the southern part of the Pali Aike Lava Field (Santa Cruz province, Argentina). We develop discussions about formation processes of the sedimentary deposits, the chronology of the archaeological assemblages found in these deposits, and the regional palaeoclimatic implications of certain sedimentological features observed in the stratigraphy. This is a first step towards a geoarchaeological approach that aims to integrate the archaeological record of stratified rockshelters and caves within a broader biogeographical framework for southern Patagonian archaeology.

KEY WORDS: geoarchaeology, caves, Pali Aike.

* CONICET-IMHICIHU-DIPA, UBA. Saavedra 15, 50 (1083 ACA), Buenos Aires, Argentina.

E-mail: ramidus28@ fibertel.com.ar

** CIC. División Mineralogía y Petrología, Museo de Ciencias Naturales de La Plata, Argentina. UNLP.

*** Facultad de Ciencias, Universidad de la República, Uruguay. UBA. 


\section{INTRODUCCIÓN}

El campo volcánico Pali Aike (CVPA) es una de las regiones en las cuales se inició la arqueología patagónica. Los trabajos desarrollados por J unius B. Bird a partir de la década de 1930 en las cuevas Fell y Pali Aike, entre otras, proveyeron el esquema empleado para comprender la historia cultural de Patagonia meridional (Bird 1938, 1988). A su vez, algunas de las primeras muestras fechadas por el método de ${ }^{14} \mathrm{C}$ en el mundo proceden de esta región (Arnold y Libby 1951), lo que dio mayor sustento a los modelos planteados.

Recientemente se comenzó a reevaluar la arqueología de esta región en función de preguntas de carácter biogeográfico, que enfatizan el análisis de la organización espacial de las poblaciones humanas (Borrero 2002). Esto se asocia al análisis de los procesos que forman los conjuntos arqueológicos, que ha llevado a reconsiderar algunas inferencias postuladas previamente. Se están realizando estudios tafonómicos dirigidos a evaluar el potencial que presentan diferentes espacios para la preservación de materiales orgánicos y las condiciones existentes para la mezcla de materiales tafonómicos y arqueológicos (Martin y Borrero 2004; Martin et al. 2004). Estos trabajos conducen a replantear, en algunos casos, la asociación postulada entre restos de megafauna y evidencias culturales.

La geoarqueología es otra de las líneas que se desarrolla a fines de estudiar las características de los depósitos sedimentarios que contienen al registro arqueológico y comprender los procesos implicados en su génesis. En este trabajo presentamos información estratigráfica y geoarqueológica del sitio Orejas de Burro 1 (OB1), ubicado en el sector meridional del CVPA (Fig. 1), que provee evidencias estratificadas de importancia para nuestras discusiones sobre biogeografía humana.

Esta información incluye tanto los datos estratigráficos de perfiles expuestos en nuestras excavaciones, como aquellos generados por trabajos previos realizados por aficionados en otro sector de la cueva (Guerra de Fretes 1977).

\section{OBJETIVOS GENERALES Y EL APORTE DE LA GEOARQUEOLOGÍA}

El proyecto en el cual se enmarca este trabajo busca evaluar la organización geográfica de las poblaciones humanas que habitaron este espacio durante el Holoceno (Borrero 2002). Los temas discutidos incluyen las características de los rangos de acción o territorios de estas poblaciones, particularmente sus dimensiones, y el tipo de vinculaciones establecidas entre diferentes sectores del paisaje.

Sobre la base de evidencias isotópicas en restos humanos hemos postulado la existencia de territorios espacialmente más acotados que aquellos inferidos a partir de evidencias etnohistóricas. Esto es particularmente válido para aquellos individuos que consumieron regularmente recursos marinos, dado que las muestras humanas que señalan este consumo se encuentran restringidas a una estrecha franja espacial no mayor a 100 $\mathrm{km}$ de ancho desde las costas marinas del océano Atlántico y el estrecho de Magallanes (Borrero et al. 2001; Barberena 2002). De este modo, los isótopos estables proveen evidencias de las distancias usualmente circuladas por estos individuos.

Otro tipo de evidencias arqueológicas relevante para una discusión biogeográfica se asocia a la intensidad de uso humano de puntos específicos del espacio. Dado que Pali Aike -y Patagonia meridional en general- constituye un paisaje heterogéneo en términos geológicos y ecológicos, la intensidad de uso que evidencia cada sector nos informa sobre su jerarquía en relación con las decisiones humanas sobre circuitos de circulación y emplazamiento de los asentamientos. No obstante, las evidencias arqueológicas no pueden ser interpretadas en términos de intensidad ocupacional sin una evaluación previa de los procesos de formación de los depósitos que las contienen (Farrand 1993, 2001; Bailey y Woodward 1997). Este es uno de los puntos de conexión entre la geoarqueología y las preguntas biogeográficas mencionadas.

Tal como lo han definido Martin y Borrero (2004), el CVPA está constituido por dos paisajes superpuestos. Una de las particularidades de esta región es la existencia de un paisaje subterráneo conformado por numerosas cuevas, aleros, cámaras y galerías volcánicas. Algunos de estos contextos habrían presentado un atractivo particular para los grupos humanos, que los habitaron en forma reiterada (p.e. Massone 1981; Sanguinetti de Bórmida 1976; B ird 1988). Por lo tanto, el estudio de la historia del relleno sedimentario de estos espacios es un objetivo principal a nivel geoarqueológico (Farrand y 
McMahon 1997; Favier Dubois y Borrero 1997). A nivel geoarqueológico específico, nuestros objetivos se agrupan en tres dimensiones de trabajo (Waters 1992; Zárate y Prieto 1994). En primer lugar, el estudio de los procesos de formación del registro, a fines de estimar el aporte de los distintos agentes potencialmente implicados. En segundo lugar, el establecimiento de la cronología relativa y/o absoluta de los depósitos mediante el análisis de superposición de estratos y dataciones absolutas. Como hemos mencionado, este punto es de particular importancia para nuestros objetivos, dado que contribuye a evaluar las tasas de sedimentación y la existencia de discontinuidades estratigráficas. Esto, a su vez, es fundamental para evaluar la intensidad de las ocupaciones humanas. Por último, nos interesa evaluar la existencia de evidencias sedimentarias locales que puedan asociarse a fluctuaciones climáticas regionales. La existencia de secuencias climáticas en esta región (Zolitschka et al. 2004; $\mathrm{H}$ aberzettl et al. 2005) es de gran utilidad para la interpretación del posible significado de los eventos registrados en este sitio. También se emplea información procedente de otras localidades (p.e. Mancini 2003).

\section{CAMPO VOLCÁNICO DE PALI AIKE (CVPA)}

EI CVPA se localiza en el extremo meridional de Patagonia, extendiéndose desde el río Coyle hasta el estrecho de Magallanes (Corbella 2002, Figura 1). Ocupa un área aproximada de $4500 \mathrm{~km}^{2}$ ubicada entre $50^{\circ}$ y $52^{\circ}$ de latitud S y $69^{\circ}$ y $71^{\circ}$ de longitud 0 y abarca un espacio actualmente comprendido en los territorios de $\mathrm{Chi}$ le y Argentina. El origen de este campo volcánico se asocia a la actividad tectónica Andino Cenozoica (D'O razio et al. 2000).

La historia de formación del CVPA es compleja e incluye diferentes eventos de efusividad volcánica que se extienden entre el Plioceno y, probablemente, el Holoceno (Skewes 1978; Corbella 1999). Estos diferentes pulsos han generado formas volcánicas particulares. Las mismas presentan cronologías variables y, por ende, meteorización y sedimentación diferente. La interacción entre estos dos niveles ha producido importantes variaciones geológicas y geomorfológicas.

Se ha propuesto una secuencia de tres pulsos volcánicos que generaron unidades volcánicas diferentes. En este trabajo empleamos la secuencia propuesta por D'Orazio y coautores

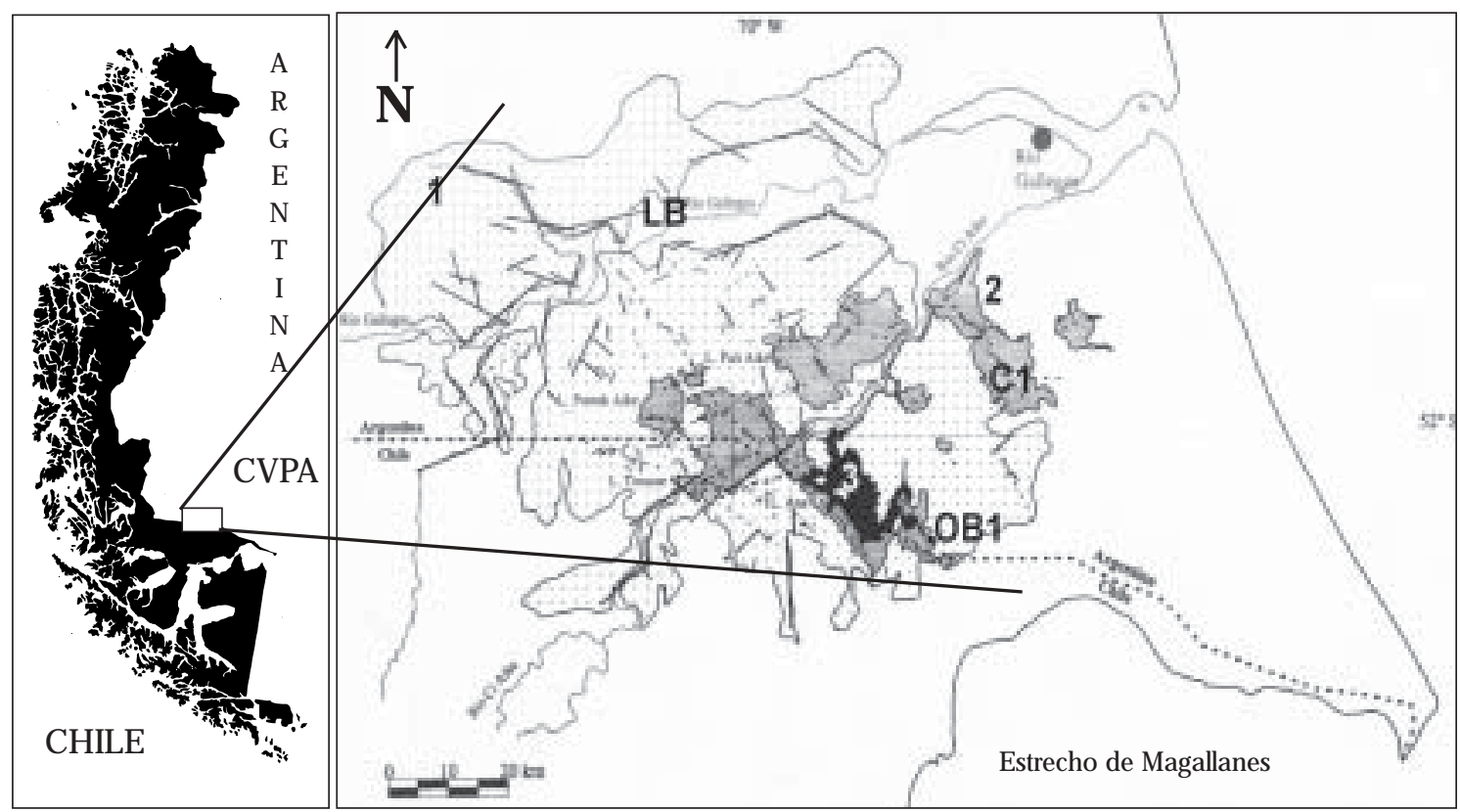

Fig. 1. Ubicación del CVPA y unidades volcánicas (modificado de D’O razio et al. 2000) Referencias sobre los sitios mencionados en el texto: 1, 2 y 3 Unidades geológicas (sensu D'O razio et. al. 2000) OB 1: Orejas de Burro 1; LB: Las Buitreras; C1: Cóndor 1. 
(2000, Fig. 1). La unidad 1 -Basal Lava Plateaustiene una cronología de 3.8 millones de años. Está representada por coladas mesetiformes de lava y no se le asignan aparatos volcánicos. Estos afloramientos constituyen un $83 \%$ de la superficie del CVPA. Conforman la totalidad de los rasgos volcánicos ubicados al norte del río G allegos, una parte considerable de los ubicados entre los ríos Gallegos y Chico, y sectores más acotados dentro del sector meridional, al sur del río Chico.

La unidad 2 -Older Cones and Lava Flows- está integrada por un total de 442 aparatos volcánicos, entre los que se diferencian maares, conos y anillos de tufa (D'Orazio et al. 2000). Estos rasgos han sido erosionados y rellenados por sedimentos. También hay coladas de lava asociadas que se encuentran relativamente meteorizadas y cubiertas por sedimentos. Esta unidad constituye el $15 \%$ del CVPA y se distribuye principalmente en los sectores central y oriental del mismo. El sitio OB1 se localiza en esta unidad.

Por último se reconoce la unidad 3, Younger Cones and Lava Flows (D'Orazio et al. 2000), que incluye los rasgos producidos por los eventos magmáticos más recientes, registrados hasta el Pleistoceno tardío y probablemente el Holoceno temprano (Corbella 1999). Se han obtenido fechas entre 0.17 y 0.01 millones de años AP para rasgos de esta unidad en la localidad Laguna Azul. Estos rasgos se encuentran espacialmente restringidos al sector SE del campo volcánico y serían producto de la efusividad del volcán Cerro Diablo (Corbella 1999). Su carácter reciente en relación con el resto de las formas volcánicas existentes les confiere una morfología particular. Los conos se encuentran muy bien preservados y presentan paredes caracterizadas por marcadas pendientes, dado que han experimentado escasa meteorización y sedimentación.

El paisaje de cuevas y aleros existentes es altamente variable, lo cual hace que Pali Aike sea un laboratorio adecuado para la evaluación de los condicionantes de la formación del registro arqueológico en este tipo de emplazamientos. Aspectos como la apertura y el número de bocas de una cueva, su ubicación y orientación geográfica y el tipo de roca de caja pueden establecer historias diferentes para la evolución de un espacio y la consiguiente preservación o destrucción del registro fósil depositado (Laville et al. 1980; Favier Dubois y Borrero 1997). El caso del sitio OB1 que presentamos en este trabajo constituye un primer paso para este tipo de análisis en la región de Pali Aike.

\section{METODOLOGÍA}

Las unidades estratigráficas que conforman el relleno sedimentario de la cueva fueron definidas y descriptas macroscópicamente de acuerdo a sus características de textura al tacto, espesor y geometría, color en seco (Munsell Soil Chart), disposición y contenido biológico o arqueológico. Los análisis de laboratorio permitieron evaluar estas definiciones. Se muestrearon los sedimentos de todas las unidades estratigráficas y rasgos reconocidos. Se tomaron muestras de mano de la roca de caja del sitio, que fueron preparadas en cortes delgados y analizadas por microscopía de polarización.

L as unidades sedimentarias fueron descriptas empleando dos categorías estratigráficas. En primer lugar, correspondiendo al nivel de análisis más general, se encuentran las unidades estratigráficas, definidas sobre la base de criterios litológicos (ver Stein 1990) y denominadas con números romanos. En segundo lugar, se registra la presencia de rasgos -antrópicos o naturales- contenidos en el interior de alguna de las unidades estratigráficas o en los límites entre las mismas. Para su denominación se combina el número romano que corresponde a la unidad con un número arábigo dado por la cantidad de rasgos en cada unidad estratigráfica (por ejemplo I.1, I.2).

El análisis granulométrico de las muestras se realizó mediante contador de partículas CILAS 1180 Liquid, previa eliminación de materia orgánica, cementos y dispersión del material con técnicas estándares. Los resultados obtenidos del análisis mecánico se representaron con métodos gráficos y se analizaron estadísticamente. El análisis estadístico consistió en el cálculo de medidas de tendencia central y de desviación empleando los coeficientes estadísticos de Folk y Ward (1957). Para el cálculo de la selección de las muestras también se empleó la fórmula propuesta por Inman (1952), que otorga un menor peso a los extremos de la distribución. Para clasificar texturalmente los sedimentos se utilizó el triángulo propuesto por Folk (1954).

La composición mineralógica de la fracción arena de los sedimentos se determinó bajo lupa binocular y análisis petrográfico por micros- 
copía de polarización de preparados a grano suelto. Se estableció además cualitativamente la redondez de los clastos mediante comparación con la escala visual de Powers (1953). La composición mineralógica de muestra total en polvo y orientada (natural) se obtuvo, además, por difracción de rayos $X$ (Difractómetro Phillips, radiación $\mathrm{Cu}$ ). La información mineralógica sobre difracción no será presentada en este trabajo.

Se determinó acidez y alcalinidad de muestras representativas de cada unidad mediante la técnica de Altamirano y coautores (1976). Se preparó para cada muestra una solución de 5 gramos de sedimento en $50 \mathrm{ml}$ de agua que fue sometida a agitación en agitador mecánico de 5.000 revoluciones por minuto durante cinco minutos. Luego de 30 minutos de reposo se procedió a determinar los valores de $\mathrm{pH}$. La lectura de estos valores se realizó mediante el empleo de un pehachímetro portátil Hanna Instruments modelo HI8424 con una precisión de $\pm 0.01 \mathrm{pH}$.

\section{SITIO OREJAS DE BURRO 1}

La información detallada sobre la excavación y las características de este sitio es presentada en otro trabajo (Franco et al. en prep.). Aquí presentamos aspectos generales necesarios para el desarrollo de nuestras discusiones.

El sitio OB 1 se localiza en el sector SE del CVPA (52ㅇ 07.769'S, 690 33.151' O, Fig. 2). Se emplaza en una cueva ubicada en el interior de un cono volcánico (Figura 3). Fechados realizados mediante $\mathrm{Ar}^{40} / \mathrm{Ar}^{39}$ sobre las rocas que conforman estos conos volcánicos proveen una edad de 0.36 millones de años AP (C orbella 1999). Su cronología y morfología permite ubicar a este cono dentro de la unidad volcánica 2 (sensu D'O razio et al. 2000), aunque en una estrecha asociación espacial con coladas y conos volcánicos que corresponden a la unidad 3. Las dimensiones generales de la cueva son aproximadamente de $12 \times 5 \mathrm{~m}$ tomando el punto central de las excavaciones como eje (Fig. 4).

Un conjunto de propiedades estructurales de las cuevas son relevantes a fines del estudio de las decisiones humanas de instalación y a fines geoarqueológicos. A nivel humano, la orientación geográfica, la posición topográfica y el número y las características de las bocas existentes determinarán las condiciones de habitabilidad y el rango de visión (Legge 1972). A nivel geoarqueológico, estas mismas propiedades condicionan la intensidad y naturaleza de los procesos de sedimentación conjuntamente con las propiedades de la roca de caja (Farrand 2001).

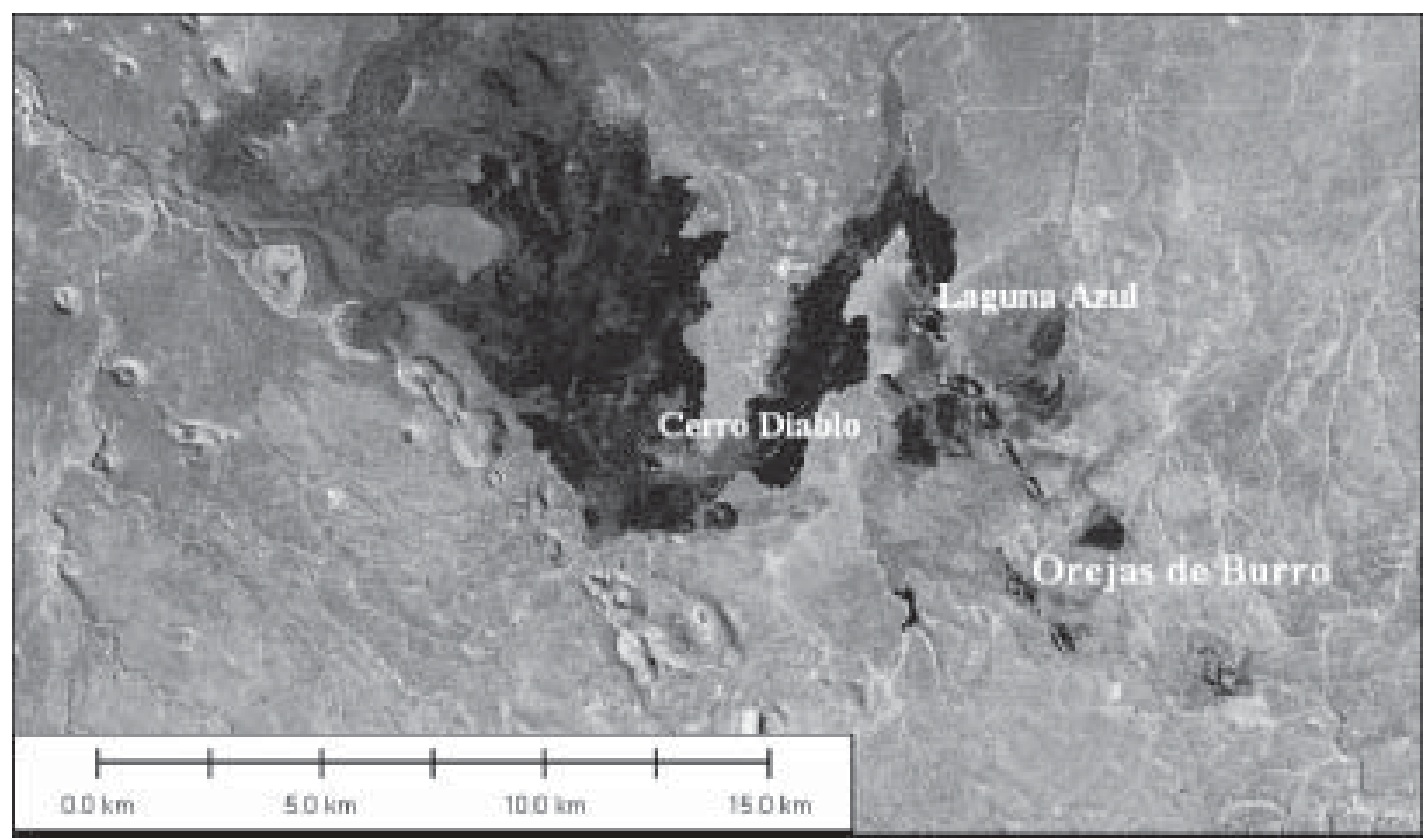

Fig. 2. Ubicación de la localidad Orejas de Burro. 


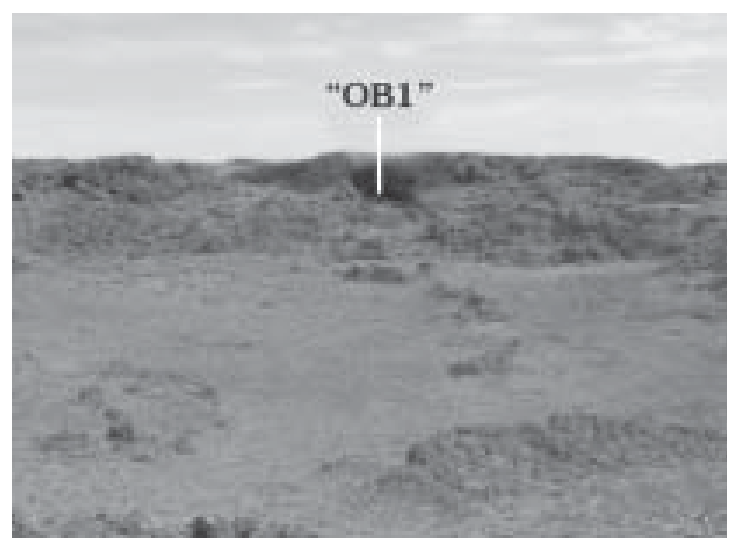

Fig. 3. Vista del sitio OB 1 desde el borde opuesto del cono volcánico.

Las propiedades que hemos evaluado en todos los sitios ubicados en reparos -ya sean cuevas o aleros- son las siguientes: posición geográfica regional, características petrográficas de la roca de caja, orientación geográfica, rango de visión, posición topográfica y presencia de restricciones a la visión (ver detalles en Barberena en prep.). El análisis de estas propiedades contribuye a evaluar las decisiones humanas de insta-

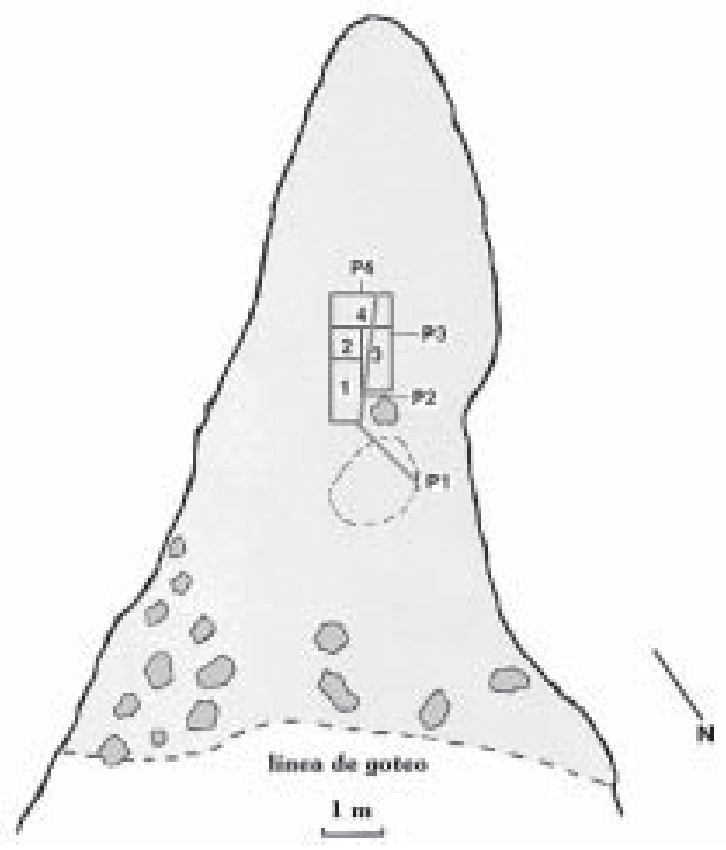

Fig. 4. Planta de la cueva y ubicación de los sectores muestreados.

Nota: La línea que une los perfiles 4 y1 representa el perfil ideal reconstruido en la Fig. 5. lación en una escala espacial micro, así como también procesos locales de formación del registro arqueológico.

En el caso del sitio OB1, la boca de la cueva presenta un rango de visión de 40ㅜ, ubicado entre $50^{\circ}$ y $90^{\circ}(\mathrm{NE})$. La posición topográfica es destacada, dado que el sitio se ubica en un sector elevado del cono volcánico, aunque existen restricciones a la visibilidad impuestas por el borde opuesto de este cono. Consistentemente con la información geológica regional, los cortes delgados realizados mostraron que la roca de caja corresponde a basaltos olivínicos con un relativo a elevado grado de meteorización que se refleja en la alteración de vesículas. Al comparar esta información petrográfica con la mineralogía de los sedimentos que conforman los diferentes depósitos se puede estimar la intensidad de la sedimentación endógena vs. exógena.

Síntesis de las características generales de la estratigrafía

Para la reconstrucción de la estratigrafía de la cueva se empleó la información procedente de los perfiles expuestos durante la excavación de las cuadrículas 1, 2, 3 y 4, ubicadas en el sector SE de la cueva, conjuntamente con el perfil expuesto en el centro de la misma, en el área alterada por excavaciones previas (Figura 4). Este último se correspondería con el emplazamiento de la excavación realizada por aficionados en la década de 1970. En dicha excavación se obtuvieron restos humanos asignables a dos individuos (Guerra de Fretes 1977). Consistentemente con esto, al realizar la limpieza de este perfil se encontró un fragmento distal de húmero humano aislado. Los sedimentos encontrados dentro de este pozo son producto de un relleno parcial posterior a la mencionada excavación.

A modo de síntesis se puede postular que en este sitio existe un continuum de menor a mayor impacto antrópico en los sedimentos que componen la estratigrafía (Figura 5). En un extremo tenemos el segmento inferior de la estratigrafía del Perfil 2, que corresponde a las cuadrículas 1 y 2 , donde no se registraron abundantes evidencias de presencia humana. Conjuntamente con lo observado en el Perfil 1, estos depósitos constituyen la fuente más confiable para la existencia de alguna señal paleoclimática, dado que una mayor intensidad en las ocupaciones humanas produciría cambios físicos y químicos 


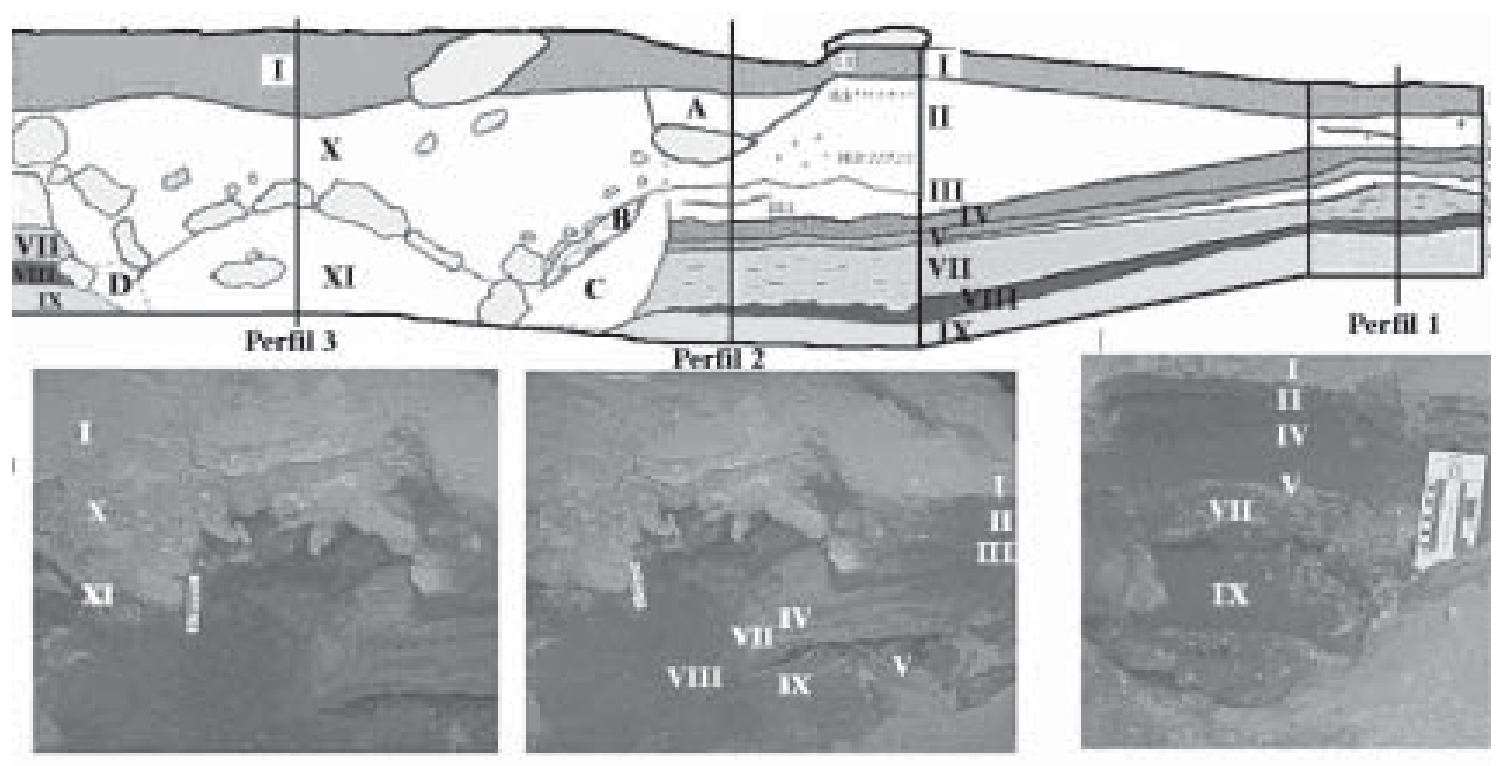

Fig. 5. Estratigrafía general de la cueva reconstruida en un perfil ideal.

en los sedimentos independientemente del clima (Laville et al. 1980; Bailey y Woodward 1997; Stein 2001).

En el otro extremo, hay un conjunto de depósitos asociados a un entierro humano recuperado en nuestras excavaciones, que corresponde al perfil 3 (Fig. 5, ver Franco et al. en prep.). Postulamos que la génesis de estos depósitos es antrópica (ver Gargett 1989).

Por último, en un nivel intermedio se encontrarían los depósitos superio res del Perfil 2. Aquí las evidencias artefactuales, ecofactuales y sedimentarias de presencia humana son muy abundantes y los sedimentos evidencian cambios físicos producto de esto. No obstante, no se puede defender que la depositación de la matriz que contiene a estos restos sea, globalmente, antrópica.

El estudio de la génesis de las unidades estratigráficas definidas sirve para estimar los patrones de sedimentación y la resolución temporal propia de los conjuntos líticos y faunísticos que las mismas contienen.

\section{RESULTADOS ESTRATIGRÁFICOS Y SEDIMENTOLÓGICOS}

Describimos brevemente tres perfiles representativos de los diferentes contextos estratigráficos registrados (Fig. 5). El perfil 1 se ubica fuera de nuestras excavaciones. Su descripción no es profundizada en el texto, aunque sí nos interesa profundizar la comparación de los perfiles 1 y 2 , ubicados a $4 \mathrm{~m}$ de distancia, a fines de diferenciar los procesos de sedimentación que han actuado en una gran parte de la cueva de otros de carácter restringido. Esto puede contribuir a la evaluación de la génesis natural o antrópica de estos depósitos.

Características estratigráficas y sedimentológicas del Perfil 2

El perfil 2 resultó expuesto a partir de la excavación de las cuadrículas 1 y 2 (ver Figs. 5 y 6). Las unidades estratigráficas analizadas mediante análisis granulométricos son la II, VII, VIII y IX.

Sobre los basaltos de la roca de base se reconoce la unidad IX, de aproximadamente 20 $\mathrm{cm}$ de espesor, constituida por un material arenoso de color gris oscuro y estructura masiva. El tamaño de grano decrece de base a techo. Se trata de una arena fina bien seleccionada con una distribución granulométrica unimodal y asimetría positiva (Tabla 1, Fig. 7D). La muestra está compuesta por clastos bien redondeados a redondeados de composición lítico-cuarzosa, cuyo origen es mayormente exógeno. Inclusive hay clastos basálticos con una composición semejante a la 


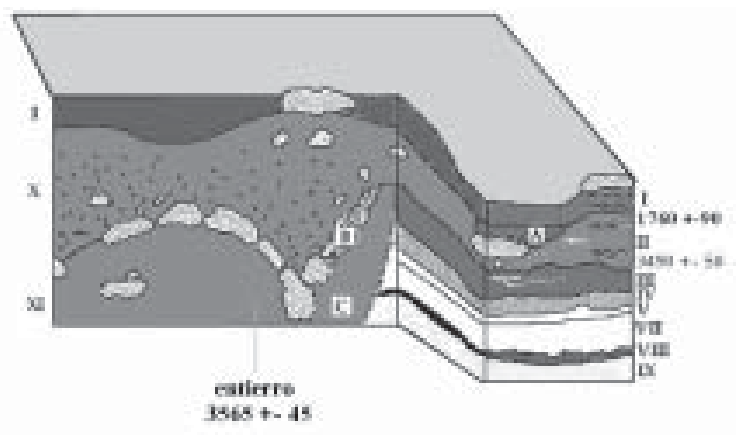

Fig. 6. Estratigrafía de los perfiles 2 y 3 (O y $\mathrm{N}$ de la excavación).

Nota: los números romanos designan a las unidades estratigráficas y las letras a los rasgos

de la roca de caja que, sin embargo, se encuentran redondeados, lo cual implica que han sido transportados desde el exterior de la cueva. Su área de procedencia se encontraría, no obstante, dentro del campo volcánico. A partir de la curva de truncamientos se infiere que los mecanismos de transporte involucrados en la movilización de los clastos corresponden a reptación (60\%) y saltación $(25 \%)$, que representan un $85 \%$ de la carga transportada (Fig. 8). Los granos correspondientes a las fracciones limo y arcilla pueden corresponder a suciedad de granos transportados por el viento. El valor de $\mathrm{pH}$ de esta muestra 9.33- es alcalino (Fig. 9).

Sigue en contacto neto la unidad VIII, integrada por sedimentos arenosos de color marón rojizo oscuro y estructura masiva. Se registró una notoria abundancia de pequeñas partículas de carbón y hollín que tiñen la fracción clástica de los sedimentos, confiriendo su color oscuro a la unidad. El tamaño medio de los clastos corresponde a arenas medias. Su distribución es unimodal (Fig. 7C). Las mismas están bien seleccionadas y tienen igual composición mineralógica que la unidad IX. Los mecanismos de transporte interpretados de las gráficas fueron la reptación $(50 \%)$ y la saltación (40\%). En este caso, al igual que en el anterior, la muestra presenta una distribución cercana a la normal, lo cual puede observarse en la semejanza de los valores de media y mediana. Conjuntamente con los valores elevados de curtosis obtenidos, esto refuerza la buena selección de las muestras y sugiere que habría un único agente de transporte implicado en su depositación. El valor medio de pH de esta uni- dad es de 9.63, siendo también alcalino.

Esta unidad pasa en contacto neto e irregular a la unidad VII, cuyo espesor varía entre 3 y $4 \mathrm{~cm}$. Se trata de un limo de color gris rojizo oscuro y estructura masiva. Presenta agregados de arcilla y nódulos dispersos de carbonato de calcio $\left(\mathrm{CaCO}_{3}\right)$. El análisis granulométrico permitió clasificarla como un limo arenoso con distribución bimodal, cuya moda principal se ubica en arena gruesa y la secundaria en limo medio (Fig. 7B). La selección de esta unidad es pobre, lo cual se refleja en su distribución platicúrtica (Tabla 1), y la asimetría es negativa. La composición mineralógica de la fracción mayor a $2.5 \phi$ (arena fina y tamaños mayores) es de un $80 \%$ de basaltos bien redondeados y un $20 \%$ de cuarzo redondeado. Esta sería la fracción transportada por reptación. A su vez, los sedimentos ubicados entre 2.5 y $3 \phi$ (arenas finas exclusivamente) están compuestos por un $50 \%$ de granos de cuarzo y un $40 \%$ de granos de basalto, en ambos casos redondeados. En la fracción 3/3.5 \& (arena muy fina) también hay abundancia de líticos volcánicos y cuarzos, acompañados en forma subordinada por feldespatos, vidrios volcánicos con vesículas alteradas, augita, hornblenda e hipersteno.

Los mecanismos de transporte involucrados en la movilización de la muestra total son la reptación $(20 \%)$, la saltación $(20 \%)$ y la suspensión de tiempo corto (60\%). A diferencia de lo observado en las muestras previas, en este caso los limos y arcillas -transportados por suspensiónconstituyen más de un $50 \%$ del sedimento (Fig. 8). El valor de $\mathrm{pH}$ de esta muestra es de 9.99 (Fig. 9), constituyendo el caso de mayor alcalinidad. Esto se relaciona con la abundancia de carbonatos registrada macroscópicamente.

La unidad V, de $3 \mathrm{~cm}$ de espesor, yace en concordancia neta sobre la unidad anterior y está compuesta por sedimentos limo arcillosos de color marrón claro oliva que presentan abundante $\mathrm{CaCO}_{3}$ pulverulento, representando el caso de mayor abundancia dentro de la secuencia. Este carbonato produce una cementación incipiente, lo cual confiere una importante compactación a la unidad. Los sedimentos limo arenosos que componen la unidad IV se apoyan en límite neto sobre los materiales anteriores, presentan color marrón oscuro y estructura masiva. Hacia arriba en contacto neto se identifica la unidad III, limo arcillosa, masiva y de color marrón oscuro. Hay presencia de carbones y huesos. Se registró la 
TABLA 1. Parámetros estadísticos de las muestras de sedimentos

\begin{tabular}{|c|c|c|c|c|c|c|c|}
\hline Muestra & Media (phi) & $\begin{array}{c}\text { Mediana } \\
\text { (phi) }\end{array}$ & $\begin{array}{c}\text { Seleeción } \\
\text { (Inman 1952 }\end{array}$ & $\begin{array}{c}\text { Selección } \\
\text { (Folky Ward 1957) }\end{array}$ & Kurtosis & Asimetría & $\begin{array}{c}\text { Clasificación } \\
\text { (Folk 1954) }\end{array}$ \\
\hline II & $\begin{array}{c}2.3 \\
\text { arena fina }\end{array}$ & 1.6 & $\begin{array}{c}2.35 \text { muy } \\
\text { mal selecc. }\end{array}$ & $\begin{array}{c}2.29 \text { muy mal } \\
\text { selecc. }\end{array}$ & $\begin{array}{c}1.12 \\
\text { leptocúrtica }\end{array}$ & $\begin{array}{c}0.62 \text { muy } \\
\text { asimétrica posit. }\end{array}$ & arena limosa \\
\hline VII & $\begin{array}{c}3.96 \text { arena } \\
\text { muy fina }\end{array}$ & 4.5 & $\begin{array}{c}3 \text { muy mal } \\
\text { selecc. }\end{array}$ & $\begin{array}{c}2.71 \text { muy mal } \\
\text { selecc. }\end{array}$ & $\begin{array}{c}0.71 \\
\text { platicúrtica }\end{array}$ & $\begin{array}{c}-0.15 \\
\text { negativa }\end{array}$ & limo arenoso \\
\hline VIII & $\begin{array}{c}1.23 \text { arena } \\
\text { media }\end{array}$ & 1.1 & $\begin{array}{c}1.15 \text { mal } \\
\text { selecc. }\end{array}$ & $\begin{array}{c}1.66 \\
\text { mal selecc. }\end{array}$ & $\begin{array}{c}1.18 \\
\text { leptocúrtica }\end{array}$ & $\begin{array}{c}0.29 \\
\text { positiva }\end{array}$ & arena \\
\hline IX & $\begin{array}{c}2.4 \\
\text { arena fina }\end{array}$ & 2.3 & $\begin{array}{c}0.7 \text { bien } \\
\text { selecc. }\end{array}$ & $\begin{array}{c}1.1 \\
\text { mal selecc. }\end{array}$ & $\begin{array}{c}2.04 \text { muy } \\
\text { leptocúrtica }\end{array}$ & $\begin{array}{c}0.59 \\
\text { positiva }\end{array}$ & arena \\
\hline XI & $\begin{array}{c}2.93 \\
\text { arena fina }\end{array}$ & 2 & $\begin{array}{c}3.1 \text { muy mal } \\
\text { selecc. }\end{array}$ & $\begin{array}{c}2.83 \text { muy mal } \\
\text { selecc. }\end{array}$ & $\begin{array}{c}0.69 \\
\text { platicúrtica }\end{array}$ & $\begin{array}{c}0.49 \text { muy } \\
\text { asimétrica posit. }\end{array}$ & arena limosa \\
\hline
\end{tabular}

Nota: el cálculo de los parámetros estadísticos y la clasificación en términos de selección, kurtosis y asimetría se realizó de acuerdo a Folk y Ward (1957; ver Scasso y Limarino 1997). La selección también se calculó de acuerdo a Inman (1952).

existencia de un rasgo de origen antrópico (III.1), que corresponde a una lente bien definida de carbones y cenizas.

Hacia el tope de la pila sedimentaria se reconoce la unidad II, limo arenosa, masiva y de color marrón oscuro, que presenta un abundante contenido artefactual y ecofactual que incluye moluscos marinos en abundancia. La depositación de carbonatos es relativamente importante, concentrándose alrededor de huesos y en las caras superiores de bloques desprendidos de la roca de caja. El valor medio de pH es de 9.05, representando el caso de mayor acidez dentro del sitio, aunque se mantiene dentro de un campo de valores alcalinos. Estos sedimentos se caracterizan por una distribución bimodal de tamaños, con moda principal en arena gruesa y secundaria en limo medio (Fig. 7A). La muestra está muy pobremente seleccionada, lo cual se refleja en su distribución platicúrtica y su asimetría es muy positiva (Tabla 1). En la fracción mayor a 2.5 \$ se registró un $80 \%$ de basalto y un $20 \%$ de cuarzos y feldespatos, todos con evidencias de redondeamiento por transporte. En forma subordinada se observaron fragmentos líticos sedimentarios. En la fracción 2.5/3 中 aumenta la proporción de cuarzos y feldespatos, que alcanzan respectivamente un 40 y $20 \%$ de la muestra, mientras que los basaltos constituyen un $40 \%$.

Dado el elevado grado de impacto antrópico en esta unidad no se pueden efectuar consideraciones acerca de la dinámica que produjo la movilización de los granos. Aunque la importante dispersión granulométrica registrada puede indicar la existencia de diversos agentes de transporte. Dentro de esta unidad, el rasgo II.1 consiste en una concentración de huesos pe- queños en una matriz con abundancia de carbonatos. La forma del mismo es laminar, descendiendo levemente hacia el S. Se fechó una muestra de carbones procedente de la misma a una profundidad de $33-37 \mathrm{~cm}$, obteniéndose una edad de $1760 \pm 70$ años ${ }^{14} \mathrm{C}$ AP (LP-1462). El rasgo II.2 presenta carbones dispersos y nódulos de carbonato. Su localización coincide con el sector donde la transición a la unidad III es más difusa. Se fechó un fragmento de tibia de guanaco (Lama guanicoe) ubicado a una profundidad de 46-50 cm, obteniéndose una edad de $3490 \pm 50$ años ${ }^{14} \mathrm{C}$ AP (Ua-21901).

Finalmente, los sedimentos de la unidad I son limo arcillosos, de color marrón, presentan estructura masiva y abundancia de guano. Se registraron abundantes evidencias de presencia humana como espículas de carbón, huesos y artefactos líticos. Debajo de un bloque en superficie se reconoció la estructura I.1, ubicada entre 26 y $30 \mathrm{~cm}$ de profundidad, que se caracteriza por la abundancia de nódulos pequeños de $\mathrm{CaCO}_{3}$ y huesos de roedor.

Hacia el S de la cueva un segmento de la pila sedimentaria descripta -representado por las unidades III a IX-se encuentra cortado por una superficie de discontinuidad que corresponde a la excavación realizada para el entierro de los restos humanos (Figs. 5, 6 y 7).

Las evidencias estratigráficas y las arqueológicas sugieren una importante intensidad de uso humano en la cuadrícula 1, a la cual corresponde este perfil. Esto se evidencia en la densidad de restos faunísticos y artefactuales y en la abundante presencia de estructuras de origen antrópico. Como mencionamos, el límite entre las unidades II y III es de carácter irregular y difuso. 

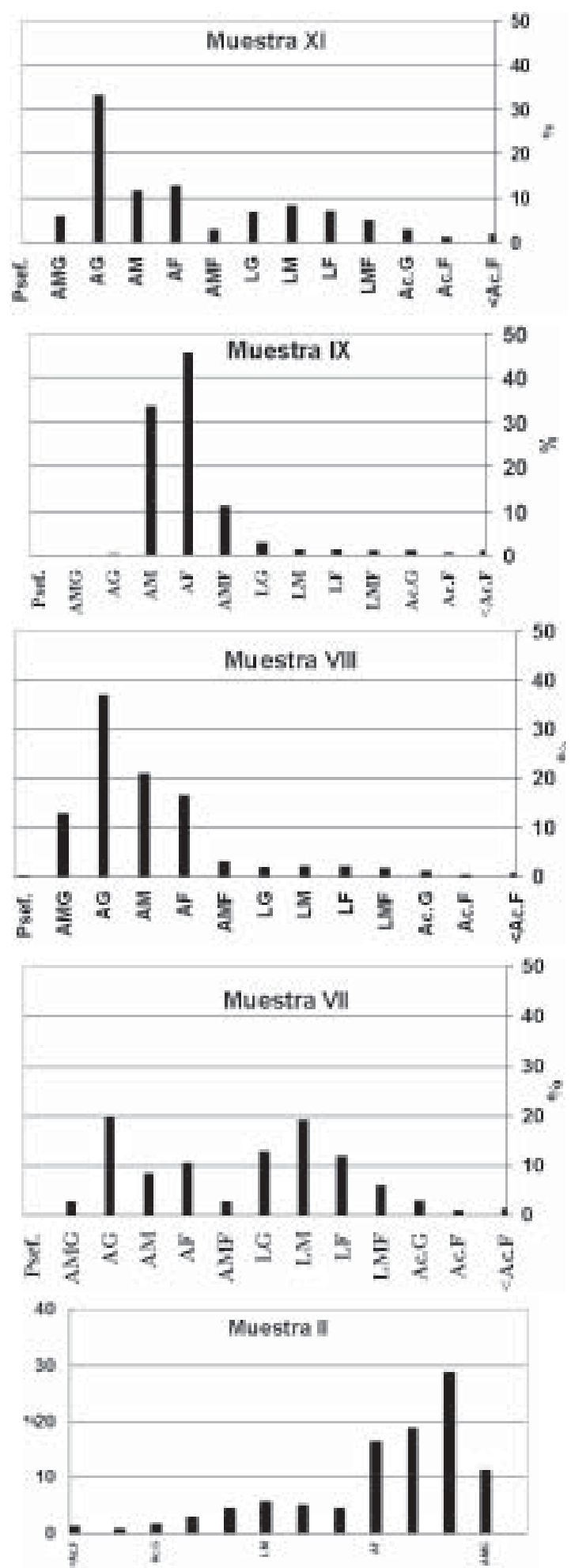

Fig. 7. Histogramas granulométricos de las muestras de
La unidad II, en particular, es heterogénea internamente, presentando sectores localizados con leves variaciones de color. Estos elementos permiten postular la existencia de un elevado impacto antrópico en los sedimentos de la cuadrícula 1, que habrían generado una redepositación de los sedimentos. En el pozo de huaqueo -perfil 1- no hay un correlato comparable a estas evidencias de intensa ocupación humana.

Correlación de los perfiles 1 y 2

Los perfiles 1 y 2 presentan importantes similitudes que sugieren la existencia de procesos de sedimentación, así como también procesos postdepositacionales, comunes. Ambos perfiles presentan arenas masivas en la base (unidad IX). Tanto sus propiedades como la posición estratigráfica sugieren un origen común. La unidad VIII, que apoya inmediatamente sobre el depósito anterior, es la segunda unidad compartida. Aunque existe una leve diferencia en la intensidad del color, que es más oscuro en la cuadrícula 1, un mismo proceso de depositación es defendible, nuevamente sobre la base de la posición estratigráfica y las propiedades texturales generales. La unidad VII, caracterizada por la abundancia de sedimentos finos y carbonatos, también ha sido reconocida en ambos perfiles. $L$ a unidad $V$, que corresponde a un delgado estrato conformado por sedimentos finos altamente cementados por carbonatos, presenta ciertos rasgos diagnósticos que sugieren su presencia en ambos perfiles. En ambos casos los límites inferior y superior son netos, aunque irregulares. Una hipótesis a considerar es que esta unidad refleje la paleo superficie de la cueva en un período de intensa circulación de agua y precipitación de carbonatos.

EI caso de la unidad IV resulta menos claro, aunque también hay elementos que sugieren un origen común para lo registrado en ambos perfiles. Esta unidad apoya sobre la unidad $V$ en ambos casos. Las propiedades registradas son semejantes, tratándose de sedimentos limo arenosos con estructura masiva. No obstante, en

sedimentos. Códigos: Psef.: psefitas, AMG : arena muy gruesa, $A G$ : arena gruesa, $A M$ : arena media, $A F$ : arena fina, $A M F$ : arena muy fina, $L G$ : limo grueso, LM: limo medio, LF, limo fino; LMF: limo muy fino, LMF: limo muy fino, Ar. G: arcillas gruesas, Ar. F: arcillas finas, < Arc. F: menor a arcillas finas. 


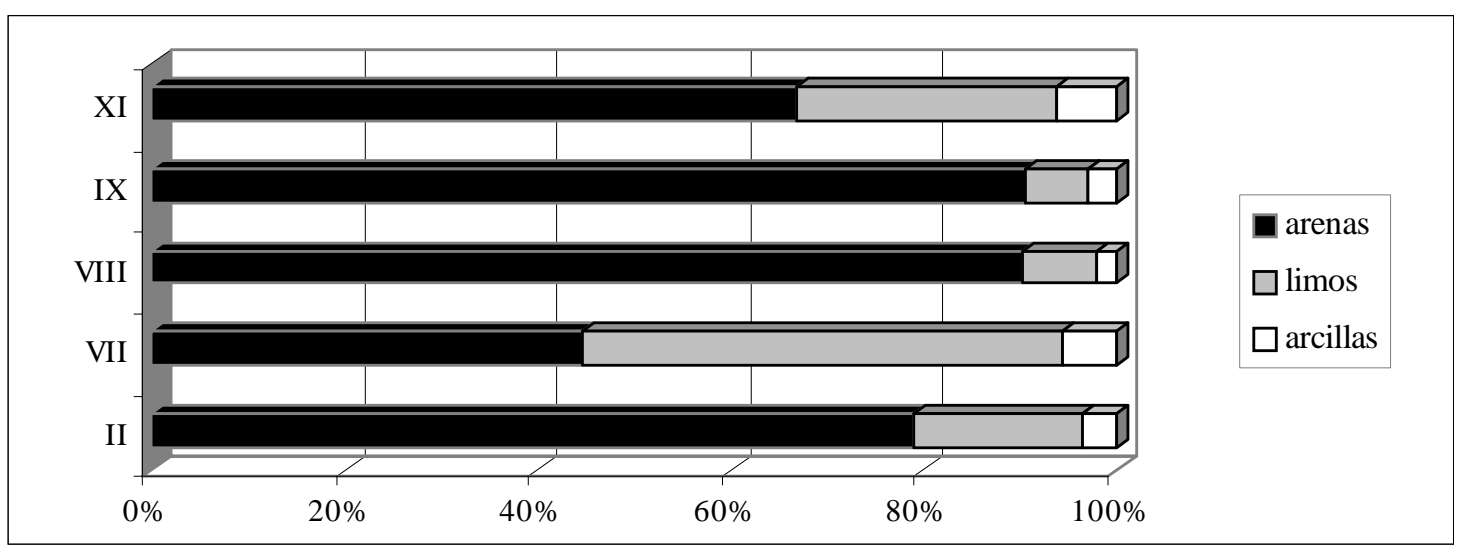

Fig. 8. Abundancia de las principales fracciones granulométricas

el perfil del pozo de huaqueo son considerablemente menores las evidencias de precipitación de carbonatos. Esto puede deberse a la existencia de diferencias a escala micro dentro del ambiente de la cueva, o a que ambos casos responden a procesos independientes de depositación. Aunque no descartamos esta última posibilidad, consideramos que la primera es más plausible. L a unidad II ha sido reconocida en ambos perfiles. La misma presenta una mayor potencia en la cuadrícula 1. Por último, la unidad I también fue registrada en los perfiles 1 y 2 . Corresponde a los sedimentos limo arcillosos ubicados en la superficie actual de la cueva, con gran abundancia de guano.
Características estratigráficas y sedimentológicas del Perfil 3

El perfil 3 corresponde a la zona de la excavación donde se recuperó un entierro humano múltiple. La estratigrafía se encuentra sumamente transformada con respecto a los perfiles 1 y 2 descriptos. Una muestra de la unidad XI fue analizada granulométricamente en el contador de partículas.

La unidad XI constituye la base de este perfil y se encuentra en contacto con los basaltos de la roca de caja. Esta unidad corresponde a la matriz del entierro, que presenta una proporción elevada de materia orgánica. Hacia el $\mathrm{N}$, esta

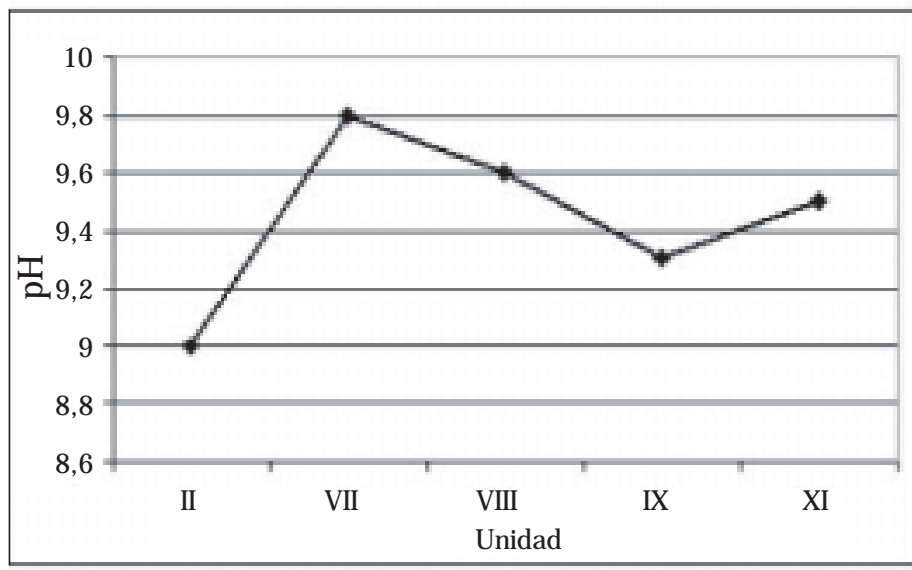

Unidad
II
II
VII
VII
VIII
VIII
IX
XI
XI

$\begin{array}{cc}\text { pH } & \text { Caracterización } \\ 9.15 & \text { Fuertemente alcalino } \\ 8.95 & \text { Fuertemente alcalino } \\ 9.99 & \text { Fuertemente alcalino } \\ 9.98 & \text { Fuertemente alcalino } \\ 9.65 & \text { Fuertemente alcalino } \\ 9.62 & \text { Fuertemente alcalino } \\ 9.33 & \text { Fuertemente alcalino } \\ 9.44 & \text { Fuertemente alcalino } \\ 9.56 & \text { Fuertemente alcalino }\end{array}$

Fig. 9. Información de pH.

Nota: las muestras II, VII, VIII y XI fueron analizadas por duplicado. En dichos casos se graficó un valor medio. 
unidad está en contacto -al menos- con las unidades IX, VIII, VII y V por medio de una discontinuidad erosiva relacionada con la excavación de la fosa del entierro (Figs. 5 y 6).

Esta unidad estratigráfica se caracteriza por una gran abundancia de restos vegetales disgregados en fragmentos pequeños. A su vez, entre los esqueletos y la roca de caja se recuperó en ciertos sectores una camada de vegetales teñida con ocre. También se encontraron restos óseos de guanaco y roedor. Los sedimentos se caracterizan por una distribución bimodal de tamaños con moda principal en arena gruesa y secundaria en limo medio, muy pobremente seleccionada, de asimetría muy positiva y platicúrtica (Fig. $7 \mathrm{E}$, Tabla 1). Esta muestra presenta los valores de selección más elevados y constituye el caso de curva más platicúrtica. Ambas medidas marcan que es la muestra con peor selección granulométrica dentro de todas las analizadas. El pH medio de esta unidad es de 9.5, de carácter alcalino, lo cual favorece una buena preservación de los restos óseos humanos. A nivel mineralógico, se observó en la fracción mayor a 2.5 p un $80 \%$ de basaltos redondeados, un $15 \%$ de feldespatos y un $5 \%$ de cuarzo. En la fracción 2.5/3 q aumenta la proporción de cuarzos y feldespatos, que alcanzan conjuntamente un $70 \%$ de la muestra, mientras que los basaltos constituyen un $30 \%$. Se observaron abundantes fragmentos de carbón en esta fracción.

Dado que esta muestra se genera a partir de la redepositación antrópica de unidades estratigráficas preexistentes, la información granulométrica no puede emplearse para reconstruir los procesos sedimentarios. Sin embargo, estos datos son importantes para evaluar, en conjunto con la información estratigráfica, la procedencia de dichos sedimentos en la escala local de la cueva. El histograma correspondiente a la muestra XI es semejante al de la muestra VII, que es una de las unidades interceptadas por la excavación de la fosa (Fig. 7). Desde un punto de vista estratigráfico puede postularse que el mayor volumen de sedimento empleado para rellenar el entierro procede de dicha unidad. A su vez, las unidades VIII y IX también fueron afectadas por la excavación. Dado que las mismas tienen una granulometría predominantemente arenosa, esto explica el enriquecimiento en arenas gruesas que presenta la unidad XI con respecto a la VII. Por lo tanto, la unidad XI sería un estrato artificial formado a expensas del material sedimentario de las unidades IX, VIII y VII (ver Gargett 1989). La información mineralógica señala una composición similar con respecto a dichas unidades.

La unidad $X$ apoya sobre la matriz del entierro y sobre numerosos bloques de la roca de caja que cubren los restos humanos presentando un contacto neto e irregular, con variaciones de hasta $15 \mathrm{~cm}$ en su posición vertical. En función de la gran abundancia de restos óseos de guanaco y de los numerosos puntos de contacto entre los mismos, esta unidad puede describirse como clasto sostén, al menos en importantes sectores de la misma, en los cuales el sedimento que constituye la matriz es relativamente escaso. Durante el avance de la excavación se observó un «entrampamiento» de los materiales óseos entre sí, predominando orientaciones horizontales y subhorizontales (Fig. 10). En estos lugares pudo observarse también la existencia de espacios huecos que no presentaban sedimentos. Algunas de estas propiedades sugieren que podría tratarse de un depósito de relleno, en el cual tanto los restos óseos como los sedimentos son depositados en forma simultánea y relativamente caótica, dando lugar a la formación de los entrampamientos y espacios vacíos registrados.

En su parte inferior del sector $\mathrm{N}$ del perfil esta unidad está delimitada por dos estructuras relacionadas con la excavación de la fosa del entierro. La estructura B está conformada por agregados arcillosos y láminas de sedimento más oscuro que buzan hacia el S (Fig. 10). Esta orientación sería coherente con una reptación de los sedimentos hacia el sector donde se ubican los entierros humanos. La estructura es heterogénea en términos de color, tiene una potencia media de 7 $\mathrm{cm}$ y presenta carbones y sectores con sedimento más oscuro altamente orgánico. El límite superior está dado por un conjunto de pequeños bloques de la roca de caja que separan a esta estructura de la unidad suprayacente. El límite inferior de la unidad es irregular y el contacto se da con los sedimentos arcillosos de la estructura $C$.

La estructura $C$ es heterogénea, aunque está compuesta fundamentalmente por sedimentos arcillosos de color gris oscuro. Está asociada al límite $\mathrm{N}$ de la excavación del entierro y correspondería también a sedimentos redepositados. En la Fig. 10 se presenta un detalle de los sectores de la estratigrafía afectados por la excavación de la fosa para este entierro. Como mencionamos, esta excavación generó la unidad estratigrá- 


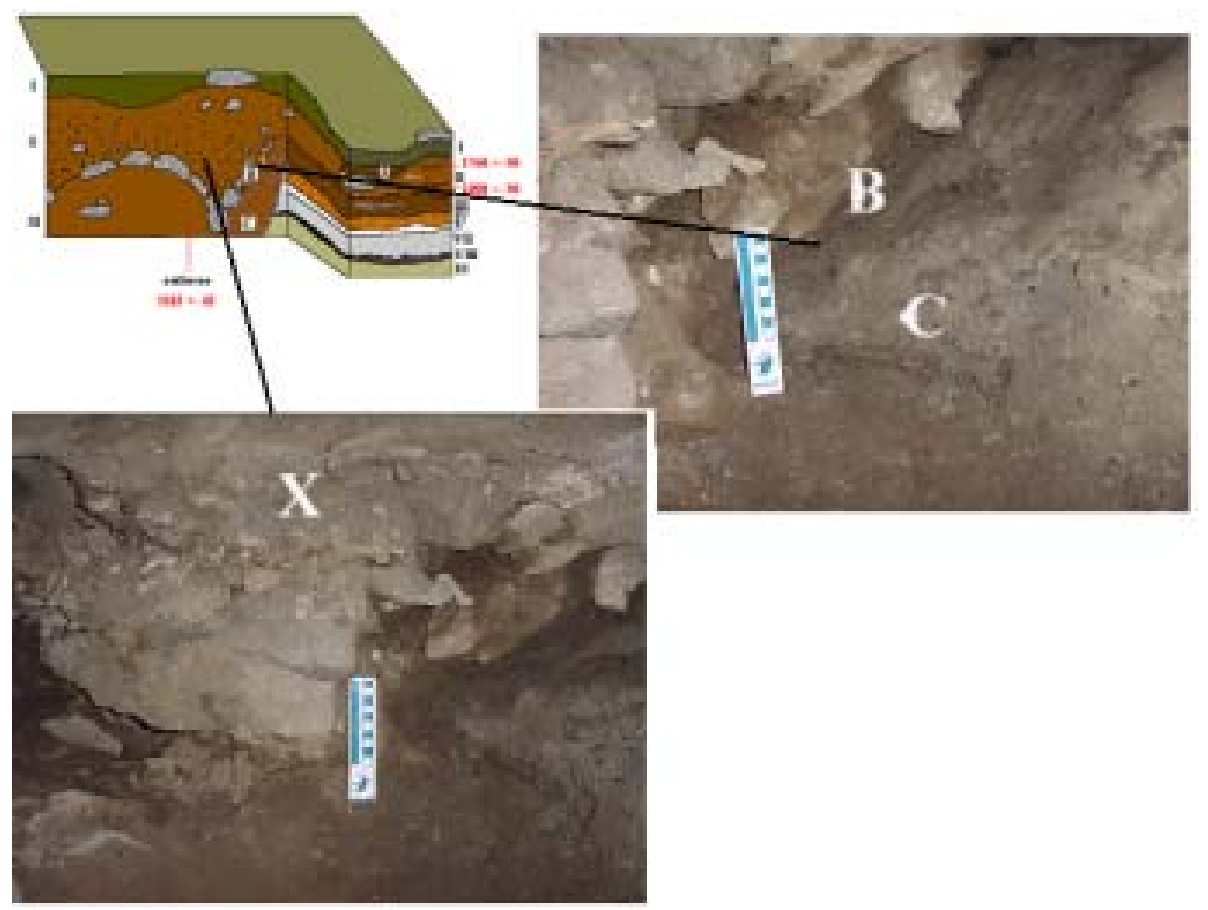

Fig. 10. Unidades estratigráficas y rasgos antrópicos producto de la excavación de la fosa.

fica XI, así como las estructuras B y C. Una hipótesis a considerar es que la génesis de la unidad $X$ también esté vinculada a la depositación del entierro. En este caso, se trataría de un relleno compuesto por sedimentos y materiales óseos dispuesto a fines de cubrir dicho entierro. Para evaluar esta posibilidad se debe contar con más fechados y con estudios de los conjuntos arqueológicos contenidos en el mismo.

Por último, la unidad I presenta aquí características similares a otros sectores de la cueva, aunque entre el límite $S$ del bloque de roca de caja y la esquina $S$ del perfil se observan diferencias. Incluimos a este sector dentro de la presente unidad, aunque lo diferenciamos con la denominación unidad I'. Aquí, los primeros $2 \mathrm{~cm}$ se caracterizan por la presencia de guano disgregado en sedimentos finos. A partir de este punto se verifica un aumento en la proporción de guano con una marcada estratificación tabular horizontal, dada por la presencia de bloques sumamente compactados. En la parte inferior de estos bloques se pudo observar la precipitación de concreciones carbonáticas. La potencia de esta capa de guano es variable en diferentes sectores del perfil, aumentando en el centro.
Por último, en el perfil 4 se detectó el límite $S$ de la estructura de entierro. Las características de las unidades ya han sido presentadas en la descripción de los otros perfiles. Nos interesa mencionar que en este perfil se combinan algunas de las unidades registradas en los perfiles 2 y 3 . En la base del perfil se repite la secuencia registrada en el perfil 2, en el límite $\mathrm{N}$ de esta estructura de entierro (unidades IX, VIII y VII). Luego siguen las unidades $X I$ y $X$, que representan el extremo $\mathrm{S}$ de la estructura de entierro. Dicho límite se asocia a la estructura $D$, que corresponde a sedimentos de color oscuro redepositados. Finalmente, la unidad I se encuentra en la superficie, apoyando sobre la unidad $X$.

\section{ASPECTOS CLIMÁTICOS}

Usualmente se enfatiza que los depósitos sedimentarios formados en cuevas y aleros responden principalmente a condiciones locales y que esto limita su potencial para la realización de inferencias climáticas. No obstante, existen diferencias en cuanto al manejo de este tipo de datos y el alcance que se les ha concedido en relación con estas preguntas. En un extremo, investigado- 
res que trabajan en contextos kársticos situados en ambientes periglaciarios han otorgado una gran importancia a los sedimentos de aleros como línea para la reconstrucción del clima y como herramienta para la correlación de secuencias culturales procedentes de diferentes sitios arqueológicos (Laville et al. 1980). Empleando evidencias procedentes de diferentes sitios construyen una secuencia climática regional con una resolución cronológica elevada.

La aplicación de los principios metodológicos sobre los que se basa este esquema ha sido aceptada (Collins 1991) y rechazada para regiones situadas en otros contextos geomorfológicos (Bailey y Woodward 1997). Por otra parte, también se han postulado y sustentado objeciones de carácter aún más general. Farrand (2001: 4144) ha señalado que los procesos que generan la fragmentación de la roca de caja de un reparo en cualquier contexto geomorfológico son variados. Estos procesos pueden ser de carácter climático, aunque también pueden deberse a eventos sísmicos, fragmentación postdepositacional u otros. Dado que las inferencias climáticas propuestas por Laville y coautores (1980) se basan en la morfología y el tamaño de los bloques eboulis-, estos procesos alternativos deben ser evaluados.

Adoptar una postura crítica en este sentido es muy importante, lo cual implica considerar cada cueva o alero individualmente en términos de su marco tectónico, sus propiedades morfológicas y sedimentológicas, tratando de discriminar el peso de los factores locales vs. regionales potencialmente climáticos- en la formación de los depósitos. Hay diferentes indicadores sedimentológicos que pueden contribuir a una reconstrucción paleoclimática. En los casos en que pueden evaluarse los agentes que depositan una determinada fracción sedimentaria en un depósito, la existencia de variaciones en la importancia cuantitativa de dicha fracción puede ser un buen indicador (Farrand 2001: 49-53). En este caso, nos centramos en el análisis de la abundancia relativa de sedimentos de tamaño mayor a limo, evaluando la existencia de correlaciones con otros indicadores sedimentológicos físicos y/o químicos.

En el caso de OB 1 hay dos segmentos de la estratigrafía del perfil 1 cuyas propiedades no pueden explicarse exclusivamente en función de las características del sitio y que, por lo tanto, pueden asociarse a variaciones climáticas regio- nales que condicionan la historia sedimentaria. Postulamos a modo hipotético su posición cronológica y el tipo de evento climático al que se asocian. La contrastación de esta propuesta tomará fuerza a partir de su evaluación en otros contextos geográficos. Las secuencias procedentes de los sitios Cóndor 1 (Barberena et al. 2005) o Las Buitreras (Eugenio 1999; Scasso y Eugenio 1999) constituyen alternativas adecuadas.

En la Fig. 11 presentamos la abundancia relativa de los sedimentos mayores a limo en las unidades estratigráficas. Las unidades IX y VIII son semejantes tanto a nivel granulométrico como mineralógico y pueden ser consideradas en forma conjunta. En las mismas predominan los sedimentos arenosos, que dan cuenta respectivamente de un 90.6 y $90.2 \%$ de las fracciones presentes. A partir de la unidad VII se verifica un abrupto descenso en la proporción de arenas, que baja a $44.5 \%$. La unidad V no fue analizada en el contador de partículas y es representada de modo cualitativo en la Figura 11. A nivel macroscópico se verificó el predominio de sedimentos finos aún más marcado que en la unidad VII. A partir de la unidad II aumenta nuevamente la frecuencia de arenas $(79.1 \%)$. Las unidades III y IV, que tampoco fueron analizadas por sedigrafía, son cualitativamente comparables a la unidad II.

En términos de la dinámica ambiental regional, para las unidades IXNIII se infiere una importante disponibilidad local de sedimentos de tamaño arena, pasibles de ser afectados por deflación eólica. Esto puede asociarse a una menor cobertura vegetal (Tsoar y Mÿller 1986), lo cual se correspondería con momentos de aridez regional.

El segundo segmento de la estratigrafía incluye las unidades VII y V. En ellas se verifica no sólo una disminución en la abundancia de arenas, sino también un aumento en la presencia de carbonatos. Consistentemente, en estas unidades se han obtenido los valores más elevados de $\mathrm{pH}$. Dado que no hay elementos para defender una disminución en la competencia del agente eólico a lo largo del Holoceno, sugerimos que la disponibilidad regional de arenas en condiciones de ser transportadas por el viento sería menor y que el aporte eólico sería de naturaleza fina y distal. Por otra parte, habría una mayor circulación de agua -probablemente en forma estacional- que posibilitaría el aumento en la precipitación de carbonatos. Por lo tanto, a modo 
de hipótesis proponemos que esta unidad se asocia a momentos de mayor disponibilidad de agua en la cueva y en la región.

La mayor abundancia de arenas en las unidades IV, III y II podría sugerir un retorno a condiciones de mayor aridez relativa. No obstante, dadas las abundantes evidencias de ocupación humana allí recuperadas no consideramos defendible proponer inferencias paleoclimáticas a partir de estos datos.

PARÁMETROS CRONOLÓGICOS Y FORMACIONALES PARA LA INTERPRETACIÓN DE LOS CONJUNTOS ARQUEOLÓGICOS

A priori, se puede plantear que en este sitio hay tres conjuntos arqueológicos diferenciables a partir de criterios estratigráficos. La información presentada contribuye a evaluar los términos cronológicos adecuados para su interpretación. Aquí presentamos lineamientos generales que serán discutidos a partir del estudio de los materiales arqueológicos en marcha.

Sobre la base de criterios estratigráficos y contextuales, el entierro humano múltiple puede defenderse como un único evento de depositación. Esto implica que tanto los cuatro individuos como el sedimento que los aloja fueron depositados en forma conjunta. En este sentido, este conjunto presenta una gran resolución temporal, aunque la migración vertical de materiales no asociados puede haber ocurrido. Esto aplica particularmente a restos óseos de guanaco hallados en la matriz del entierro -unidad XI-, algunos de los cuales podrían estar asociados al mismo y otros no (L'Heureux en prep.). El conjunto humano puede servir para evaluar la existencia de variaciones en la preservación condicionadas por la edad de los individuos, la posición de entierro o procesos postdepositacionales (Martin en prep.). Planteamos que el tiempo puede considerarse como una variable constante.

El conjunto arqueológico ubicado por sobre el entierro presenta un caso diferente (Figura 5). No podemos definir la forma de depositación del mismo, aunque sí planteamos hipótesis alternativas al respecto que deben evaluarse en función del análisis de los restos óseos, líticos y de la cronología. Consideramos que esta discusión se debe apoyar en tres instancias de análisis: el tiempo implicado en la depositación del conjunto, la procedencia de los materiales incluidos y, luego, la relación entre este conjunto

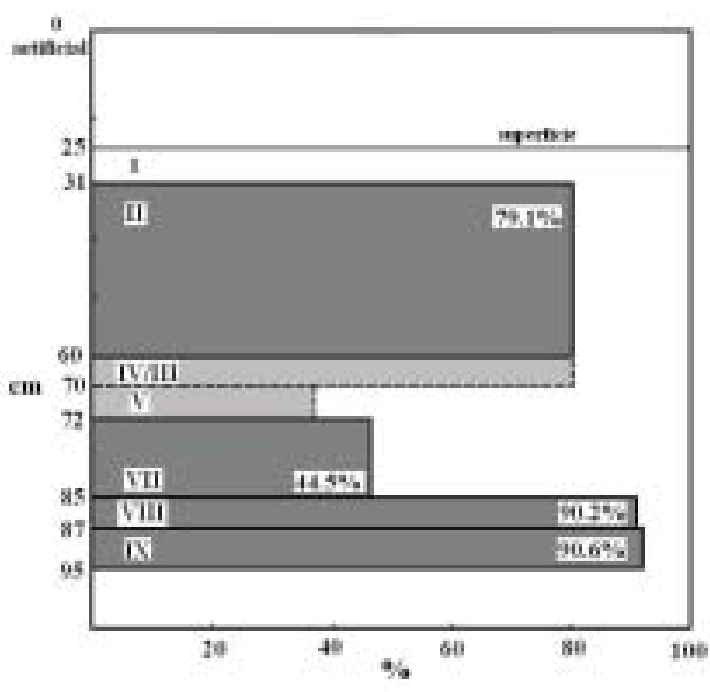

Fig. 11. Abundancia de arenas.

Nota: el ancho de cada barra está en relación con la potencia estratigráfica de la unidad que representa.

y el entierro subyacente.

Con respecto al primer tema, la depositación del conjunto puede haber sido simultánea 0 atricional y también es posible que se combinen ambos tipos. La fábrica del depósito muestra abundantes contactos entre huesos clasto sostén-, la existencia de espacios vacíos entre los mismos y una distribución irregular del sedimento, lo cual sugiere una depositación simultánea y caótica del conjunto. Sugerimos como hipótesis que este conjunto fue depositado en forma conjunta, constituyendo un relleno.

En segundo lugar se mencionó la procedencia de los materiales incluidos en el conjunto. La resolución del tiempo implicado en la depositación afectará las alternativas posibles para este análisis. Aún en el caso que los materiales hayan sido depositados conjuntamente, la procedencia temporal de los mismos puede ser variable. Los fechados actualmente en marcha contribuirán a resolver esto.

Por último, está la relación entre este conjunto y el entierro subyacente, que puede ser o no de penecontemporaneidad. La primera alternativa implicaría que el conjunto forma parte de las conductas de tratamiento de los muertos. El contacto directo entre el límite superior del entierro y el inferior del conjunto de la unidad $X$ puede sugerir una asociación conductual entre ambos, aunque esto debe ser evaluado. 
En relación con los conjuntos arqueológicos recuperados en la cuadrícula 1 y en el sector $\mathrm{N}$ de la cuadrícula 2, los fechados muestran una depositación tiempo-transgresiva. A partir de estos fechados puede realizarse una estimación cualitativa de los procesos de sedimentación, que habrían sido lentos.

\section{DISCUSIÓN Y CONCLUSIONES}

La correlación con otros sitios en abrigos rocosos contribuye no sólo a evaluar la generalidad de los resultados obtenidos en OB 1, sino que también permite comprender las variables que condicionan la formación de registros estratificados en Pali Aike. El otro caso que presenta información geoarqueológica que puede ser comparada es el de cueva Las Buitreras (Sanguinetti de Bórmida 1976; Eugenio 1999; Scasso y Eugenio 1999), ubicada a $500 \mathrm{~m}$ del río Gallegos en el sector septentrional del campo volcánico y a una distancia aproximada de $60 \mathrm{~km}$ de OB1. Se observan aspectos compartidos y diferencias en los procesos registrados en ambos casos.

El análisis del área de captación -o catchment- de los sedimentos que conforman los depósitos de las cuevas es útil para comprender la procedencia de dichos sedimentos y las condiciones de sedimentación existentes en diferentes sectores del campo volcánico (Vita-Finzi 1978). Presentamos una discusión inicial de este tema.

En ambos sitios se registra una predominancia de clastos volcánicos básicos de procedencia local. Dado que estos sedimentos se encuentran usualmente redondeados a subredondeados, se infiere que han sido transportados, lo cual permite descartar una procedencia endógena (ver Scasso y Eugenio 1999). Sin embargo, hay diferencias mineralógicas importantes en el relleno sedimentario de ambas cuevas. En el caso de Las Buitreras, el cuarzo se encuentra como mineral acompañante en muy bajas proporciones, variando entre 1 y $5 \%$ en las diferentes capas (Scasso y Eugenio 1999: 148-149). Como mencionamos, esto es diferente en OB1. En la fracción modal de la capa IX (2.5/3 \$, arenas finas), por ejemplo, el cuarzo constituye aproximadamente un $60 \%$ de la muestra y una situación semejante se observa en el caso de la muestra correspondiente a la unidad VIII. En términos generales, en la fracción $2.5 / 3$ क de to das las muestras los cuarzos son predominantes. La fracción mayor a 2.5 \& está principalmente compuesta por basaltos redondeados, dado que probablemente responde a procesos de reptación de clastos locales. Sin embargo, el cuarzo alcanza valores de entre 5 y $20 \%$.

En resumen, OB 1 y Las Buitreras comparten un aporte importante de sedimentos de origen volcánico y procedencia local dentro de Pali Aike, aunque presentan variaciones en la frecuencia de granos de cuarzo. Esto puede ser interpretado como una diferencia en las áreas de captación de estas cuevas. Postulamos que la distancia de ambos sitios con respecto a las costas marinas del estrecho de Magallanes y el océano Atlántico condiciona algunas de estas diferencias.

Trabajos mineralógicos disponibles para depósitos ubicados en la costa norte del estrecho de Magallanes (Uribe y Zamora 1981) y en la costa atlántica meridional (Etchichury y Remiro 1967) señalan una composición dada por fragmentos volcánicos afaníticos, fragmentos líticos, cuarzos y feldespatos. En el caso del estrecho de Magallanes, estos dos últimos alcanzan en promedio un $30 \%$ del total en la fracción arena. En los depósitos costeros de pleamar y bajamar del sector meridional de la costa atlántica el cuarzo fluctúa entre un 15 y $20 \%$ de la fracción mineralógica liviana, incluyendo fragmentos de cuarzo de venas y cuarcitas (Etchichury y Remiro 1967: 360). En algunos sectores al norte del río Gallegos trabajados por Etchichury y Remiro la abundancia del cuarzo alcanza un 30\% de esta fracción. Por otra parte, en la fracción gravas predominan los fragmentos volcánicos y en forma subordinada los metamórficos. Estos últimos corresponden a esquistos con abundantes venas de cuarzo (Uribe y Zamora 1981: 156).

Tal como sugieren Etchichury y Remiro (1967: 367-369), estos depósitos son textural y mineralógicamente inmaduros, lo cual responde a su escaso transporte. Si estos conjuntos fueran transportados distancias considerables cabe esperar una desagregación mecánica de los fragmentos líticos en sus minerales componentes y un enriquecimiento en la proporción de aquellos minerales más resistentes o estables, entre los cuales se destaca el cuarzo (Scasso y Limarino 1997: 240-242). Por lo tanto, y ante la ausencia de indicadores claros sobre fuentes alternativas de procedencia, postulamos que estos conjuntos costeros podrían haber funcionado como las fuentes a partir de las cuales se derivó una parte del relleno de la cueva OB 1. 
Esto marcaría un área de captación que incluye los espacios marinos para este último sitio, mientras que el área de captación de Las Buitreras sería predominantemente interior, lo cual es coherente con su ubicación geográfica, dado que OB 1 se ubica a poco menos de $20 \mathrm{~km}$ de la costa más cercana -estrecho de Magallanesy Las Buitreras está a $60 \mathrm{~km}$ del segmento de costa más inmediato -desembocadura del río Gallegos- (ver Fig. 1). Esta sugerencia es tentativa y deberá ser profundizada a partir del análisis mineralógico de muestras procedentes de otros sitios.

Con respecto a la dinámica de depositación de los sedimentos, los procesos eólicos son el agente predominante, lo cual podría marcar un modo tafonómico (sensu Behrensmeyer et al. 1992) compartido que debe ser analizado a partir del análisis de los conjuntos faunísticos. No obstante, en el caso de las unidades inferiores de Las Buitreras se ha defendido un origen fluvial para una parte de los sedimentos (Scasso y Eugenio 1999: 159). Esto marca una diferencia con respecto a OB1, que se ubica en un contexto geomorfológico diferente donde los procesos fluviales no han producido un aporte sedimentario.

Los aspectos climáticos fueron planteados en términos cualitativos y aproximados. Nuestra inferencia con respecto a un conjunto sedimentario que responde a condiciones de mayor aridez y otro conjunto posterior asociado a condiciones de mayor humedad puede ser definida como una propuesta "flotante", ya que no hay una cronología absoluta que nos permita anclarla en relación con eventos climáticos específicos. Sin embargo, podemos postular alternativas plausibles contrastables en el futuro.

A partir de evidencias palinológicas se ha planteado que el Holoceno temprano tendría precipitaciones semejantes a las actuales, aunque en asociación con temperaturas más elevadas (Mancini 2003). Esto inclinaría el balance de la humedad efectiva en el ambiente hacia una mayor aridez, particularmente en los ambientes de estepa donde la evapo-transpiración es muy intensa. Esta situación se expresa en localidades como Chorrillo Malo 2 (Mancini 2002), La Martita (Mancini 1998) o Los Toldos (Páez et al. 1999) en una tendencia hacia el aumento en la abundancia de Asteraceae subf. Asteroideae y una disminución de Poaceae. Para el caso de Las Buitreras, Prieto y coautores (1999: 175) sugieren: las condiciones de estepa xérica se extien- den hasta ca. 8000 años A.P. (...), cuando el registro indica un cambio a una situación de mayor disponibilidad de agua entre 7.600 y 4.500 años A.P. y una situación semejante con la estepa húmeda. También en este sentido, las evidencias polínicas de cueva Fell marcan un cambio de una estepa mésica a una xérica entre 11.000 y 10.000 años ${ }^{14} \mathrm{C}$ AP -con anterioridad a las evidencias mencionadas- (Markgraf 1988). Por el contrario, para el Holoceno medio se han sugerido condiciones más frías y húmedas, que redundarían en una mayor disponibilidad de agua para el crecimiento de la vegetación.

Tentativamente, esta transición climática puede ajustarse a las variaciones granulométricas registradas en los depósitos iniciales de OB 1 (Fig. 12). La menor humedad efectiva postulada para el Holoceno temprano podría producir una mayor disponibilidad de sedimentos de tamaño arena que son transportados por el viento mediante saltación. De acuerdo con esta propuesta, el paquete sedimentario que incluye a las unidades VII y V se asociaría con condiciones de mayor humedad efectiva, que producen un aumento en la cobertura vegetal regional y una consiguiente fijación de los sedimentos de tamaño arena. Los sedimentos finos que componen mayormente a estas unidades serían transportados principalmente por suspensión y corresponderían a eólicos distales.

Este escenario es especulativo, dado que hay factores locales no asociados al clima que podrían generar variaciones en las propiedades físicas y químicas de los sedimentos. Sin embargo, defendemos que la magnitud de las variaciones registradas en estos datos puede ser explicada de forma más parsimoniosa en referencia a procesos climáticos de amplitud regional. Por otra parte, con la información actualmente disponible no podemos estimar la posición cronológica precisa o el rango temporal de estas unidades estratigráficas. Los datos presentados sirven para considerar al fechado obtenido para el de 3565 \pm 45 años ${ }^{14} \mathrm{C}$ AP como una edad mínima para las mismas, dado que procede del entierro que produjo su remoción parcial.

La disponibilidad de información con una importante resolución cronológica procedente de lagos volcánicos en Pali Aike (Zolitschka et al. 2004; Haberzettl et al. 2005) contribuirá a evaluar esta sugerencia. La posibilidad de establecer una cronología absoluta para los depósitos inferiores de OB 1 será importante para el 
desarrollo de las discusiones biogeográficas, dado que dichos depósitos muestran la ausencia de ocupaciones humanas.

Con respecto a la importancia de estas ocupaciones en la génesis de los depósitos de la cueva, hemos mencionado que se registra un continuum que va desde unidades estratigráficas que no evidencian presencia humana a otras unidades que son "creadas" antrópicamente. Por otra parte, las unidades superiores del perfil 2 presentan variadas evidencias de intensa ocupación humana para, al menos, los últimos 3.000 años AP. En la unidad II estas evidencias se asocian con los valores de $\mathrm{pH}$ más ácidos, lo cual puede relacionarse con el aporte antrópico de materiales orgánicos. N uestras inferencias deben ser profundizadas y evaluadas a partir del análisis de los conjuntos arqueológicos. Planteamos que los resultados estratigráficos presentados sugieren una intensa presencia humana en la cueva desde 2.000 o 3.000 años ${ }^{14} \mathrm{C}$ AP.

Uno de los objetivos principales de nuestro trabajo consiste en estimar los términos cronológicos y formacionales adecuados para la interpretación de los conjuntos arqueológicos contenidos en los depósitos estudiados. A su vez, el estudio de estos materiales servirá para retroalimentar, y probablemente modificar o refutar, algunas de las tendencias señaladas en este trabajo. Consideramos que este es el esquema más productivo para el desarrollo de un trabajo interdisciplinario.

Hemos sugerido un conjunto de parámetros para la interpretación de los conjuntos estratificados de OB1. La evaluación de la formación y la cronología de los depósitos contribuye a estimar las tasas de descarte de materiales arqueológicos y, en función de esto, la intensidad ocupacional humana. El trabajo geoarqueológico en secuencias estratificadas ubicadas en sectores del espacio con propiedades geográficas variables es un primer paso para el desarrollo de un esquema biogeográfico para la interpretación de las ocupaciones humanas en el campo volcánico de Pali Aike.

\section{AGRADECIMIENTOS}

Agradecemos a las siguientes instituciones por la financiación de los proyectos en los cuales se enmarca este trabajo: Agencia Nacional de Investigaciones Científicas y Técnicas ("Modos de interacción entre las poblaciones huma- nas de la Patagonia Meridional"), National G eographic Society ("H unter-G atherer Archaeology and Palaeoecology at the End of the World. Patagonia, Argentina, Southernmost South America") y Conicet (Proyectos "Magallania").

A Silvia Ametrano y Aníbal Figini del Museo de Ciencias Naturales de La Plata por su gran apoyo y por facilitar nuestro trabajo de laboratorio. A Lucas Ruiz de la Facultad de Ciencias Exactas y Naturales (UBA) por su asistencia en el procesamiento de las muestras sedimentológicas. A Nora Franco y Lorena L'H eureux que participaron de las actividades de excavación de este sitio. A Patricia Campan, J udith Charlin, Fabiana Martin, Luis Borrero y Liliana Manzi por su contribución de diferentes modos durante el desarrollo de las actividades de campo. A Flavia Morello y Manuel San Román por su colaboración y apoyo de siempre. A Karen Borrazzo, Fabiana Martin, Clara Otaola, J udith Charlin y Marcelo Cardillo por sus comentarios, que contribuyeron a mejorar el trabajo. A Irina Capdepont por la realización de los análisis de $\mathrm{pH}$ y sus importantes comentarios y a Leonidas Carrasco Letelier por los análisis de materia orgánica.

A la Compañía de Tierras Sud Argentina y al Dr. Diego Perazzo y el Sr. Marcelino Díaz por facilitar en todo sentido nuestra estadía y trabajo en la Ea. Cóndor, Sección Monte Aymond. A Aníbal Cofré por su enorme ayuda durante las actividades de campo, que fue fundamental para el desarrollo de nuestras investigaciones. En este sentido, también agradecemos a Hugo Zaldiviar y Armando Cofré.

Finalmente, a Luis A. Borrero por la revisión del trabajo y el apoyo a nuestra investigación.

\section{BIBLIOGRAFÍA}

ALTAMIRANO, A.; H. DA SILVA; A. ECHEVARRÍA; D. PANARIO y R. PUENTES. 1976. Carta de Reconocimiento de Suelos del Uruguay. Tomo III: Descripción de la unidades de suelos. Uruguay, Ministerio de Agricultura y Pesca.

ARNOLD, J. R. y W. F. LIBBY. 1951. Radiocarbon Dates. Science 113: 111-120.

BAILEY, G. y J . WOODWARD. 1997. The Klithi Deposits: Sedimentology, Stratigraphy and Chronology. En: Klithi; Palaeolithic settlement and Quaternary landscapes in northwest Greece. Vol.1: Excavation and intra-site analysis at K lithi. Editado por: G. Bailey, pp. 61-94. Cambridge, MacDonald Institute Monographs. 
BARBERENA, R. 2002. Los límites del mar. Isótopos estables en Patagonia meridional. Buenos Aires, Sociedad Argentina de Antropología.

En prep. Arqueología y Biogeografía Humana en Patagonia meridional. Tesis doctoral. MS.

BARBERENA, R.; A. BLASI y C. CASTIÑEIRA. 2005. Geoarqueología y biogeografía: el registro de cuevas en Pali Aike. Trabajo presentado en las VI J ornadas de Arqueología de la Patagonia. Punta Arenas, Chile.

BEHRENSMEYER, A.; J. DAMUTH; W. DI MICHIELE; R. POTTS; H. SUESS y S. WING. 1992. Terrestrial Ecosystems through Time. Evolutionary Paleoecology of Terrestrial Plants and Animals. Chicago, The University of Chicago Press.

BIRD, J. B. 1938. Antiquity and Migrations of the Early Inhabitants of Patagonia. The Geographical Review XXVIII:250-275.

1988. Travels and Archaeology in South Chile. Editado por: J ohn Hyslop. Iowa, University of lowa Press.

BORRERO, L. A. 2002. Modos de interacción entre poblaciones humanas en Patagonia meridional. Proyecto presentado a la ANICYT. Buenos Aires. MS.

BORRERO, L. A.; R. A. GUICHÓN; R. H. TYKOT; J . KELLY; A. PRIETO y P. CÁRDENAS. 2001. Dieta a partir de isótopos estables en restos óseos humanos de Patagonia Austral. Estado actual y perspectivas. Anales del Instituto de la Patagonia, Serie Ciencias Humanas 29:119-127.

CHARLIN, J. en prep. Análisis de la organización de la tecnología lítica en Pali Aike. Tesis Doctoral en preparación, Facultad de Filosofía y Letras, Universidad de Buenos Aires. MS.

COLLINS, M. B. 1991. Rockshelters and the Early Archaeological Record in the Americas. En: The First Americans. Search and Research. Editado por: T. D. Dillehay y D. J. Meltzer, pp. 157-181. Boca Raton, CRC Press.

CORBELLA, H. 1999. Dataciones radimétricas en Pali Aike, Patagonia austral. Actas del XIV Congreso G eológico Argentino II:265-268. Salta.

2002. El campo volcano-tectónico de Pali Aike. En: Geología y Recursos Naturales de Santa Cruz. Relatorio del XV Congreso Geológico Argentino 118:285-301. Editado por: M. J. Haller.

D'ORAZIO, M.; S. AGOSTINI; F. MAZZARINI; F. INNOCENTI; P. MANETTI; M. J. HALLER y A. LAHSEN. 2000. The Pali Aike Volcanic Field, Patagonia: slab-window magmatism near the tip of South America. Tectonophysics 321:407-427.

ETCHICHURY, M. y J . REMIRO. 1967. Los sedimentos litorales de la provincia de Santa Cruz entre Punta Dungeness y Punta Desengaño. Revista del Museo Argentino de Ciencias Naturales VI (8):323-376.

EUGENIO, E. 1999. Geoarqueología de la cueva de "Las Buitreras" (Provincia de Santa Cruz, Argentina). Praehistoria 3:135-145.

FARRAND, W. R. 1993. Discontinuity in the Stratigraphic Record: Snapshots from Franchthi Cave. En: Formation Processes in Archaeological Context. Editado por: P. Goldberg, D. T. Nash y M. D. Petraglia, pp. 85-96. Monographs in World Archaeology 17. Madison, Wisconsin Prehistory Press. 2001. Archaeological Sediments in Rockshelters and Caves. En: Sediments in Archaeological Context. Editado por: J. K. Stein y W. R. Farrand, pp. 29-66.
Salt Lake City, The University of Utah Press.

FARRAND, W. R. y J. P. MCMAHON. 1997. History of the Sedimentary Infilling of Yarimburgaz Cave, Turkey. Geoarchaeology: An International J ournal 12 (6):537-565.

FAVIER DUBOIS, C. y L. A. BORRERO. 1997. Geoarchaeological Perspectives on L ate Pleistocene Faunas from Ultima Esperanza Sound, Magallanes, Chile. Anthropologie XXXV/2:207-213.

FOLK, R. 1954. The distinction between grain size and mineral composition in sedimentary rock nomenclature. J ournal of Geology 62:344-359.

FOLK, R. y W. WARD. 1957. Brazos river bar: a study in the significance of grain size parameters. J ournal of Sedimentary Petrology 37 (2):514-521.

FRANCO, N.; R. BARBERENA y G. L'HEUREUX. en prep. EI sitio orejas de Burro 1 (Pali Aike): excavación y resultados preliminares. MS.

GARGETT, R. H. 1989. Grave Shortcomings. The Evidence for Neanderthal Burial. Current Anthropology 30 (2):157-190.

GUERRA DE FRETES, E. 1977. Informe preliminar del hallazgo de restos humanos en una de las cuevas del paraje denominado "Monte Aymond". Actas y Memorias del IV Congreso Nacional de Arqueología Argentina (2da parte). Revista del Museo de Historia Natural de San Rafael IV:101-104.

HABERZETTL, T.; M. FEY; A. LUCKE; N. MAIDANA; C. MAYR; C. OHLENDORF; F. SCHABITZ; G. SCHLESER; M. WILLE y B. ZOLITSCHKA. 2005. Climatically induced lake level changes during the last two millennia as reflected in sediments of Laguna Potrok Aike, southern Patagonia (Santa Cruz, Argentina). J ournal of Paleolimnology 33:283-302.

INMAN, D. 1952. Measures for describing the size distribution of sediments. J ournal of Sedimentary Petrology 22:125-145.

LAVILLE, H.; J. P. RIGAUD y J. SACKETT. 1980. Rock Shelters of the Perigord. Geological Stratigraphy and Archaeological Succession. Nueva York, Academic Press.

LEGGE, A. J . 1972. Cave climates. En: Papers in Economic Prehistory. Editado por: E. S. Higgs, pp. 97-10. Cambridge, Cambridge University Press.

L'HEUREUX, G. en prep. Estudio arqueofaunístico de los materiales del sitio Orejas de Burro 1. MS.

MANCINI, M. V. 1998. Vegetational changes during the Holocene in Extra-Andean Patagonia, Santa Cruz Province, Argentina. Palaeogeography, Palaeoclimatology and Palaeoecology 138:207-219. 2002. Vegetation and climate during the Holocene in Southwest Patagonia, Argentina. Review of Paleobotany and Palinology 122:101-115.

2003. Paleoecología del Cuaternario Tardío en el Sur de la Patagonia (460-52ㅇ S), Argentina. Revista del Museo Argentino de Ciencias Naturales 5 (2):273283.

MARKGRAF, V. 1988. Fell's Cave: 11,000 years of changes in paleoenvironments, fauna, and human occupation. En: Travels and Archaeology in South Chile. J. B. Bird. Editado por: J. Hyslop, pp. 196201. University of lowa Press.

MARTIN, F. M. en prep. Análisis tafonómico de los restos humanos en Orejas de Burro 1. MS.

MARTIN, F. M. y L. A. BORRERO. 2004. Mundo Subterrá- 
neo: Regional Taphonomy at the Pali Aike Lava Field, Southern Patagonia. Trabajo presentado al $69^{\text {th }}$ Meeting of the Society for American Archaeology, Montreal, Canadá. MS.

MARTIN, F. M.; A. PRIETO; M. SAN ROMÁN; F. MORELLO; F. PREVOSTI; P. CÁRDENAS y L. A. BORRERO. 2004. Late-Pleistocene Megafauna at Cueva del Puma, Pali-Aike Lava Field, Chile. Current Research in the Pleistocene 21:101-103.

MASSONE, M. 1981. Arqueología de la región volcánica de Pali Aike (Patagonia Meridional Chilena). Anales del Instituto de la Patagonia 12:95-124.

PAEZ, M.; A. PRIETO y M. MANCINI. 1999. Fossil pollen from Los Toldos locality: A record of the Late-Glacial transition in the Extra-Andean Patagonia. Quaternary International 53/54:69-75.

POWERS, M. C. 1953. A new roundness scale for sedimentary particles. J ournal of Sedimentary Petrology 23:117-119.

PRIETO, A. R.; S. STUTZ y S. PASTORINO. 1999. Arqueopalinología de la cueva Las Buitreras (Provincia de Santa Cruz, Argentina). Praehistoria 3:169-181.

RENFREW, C. 1976. Archaeology and the earth sciences. En: Geoarchaeology: Earth Science and the Past. Editado por: D. A. Davidson y M. L. Shackley, pp. 1-5. Londres, Duckworth.

SANGUINETTI DE BORMIDA, A. 1976. Excavaciones prehistóricas en la cueva de Las Buitreras, Santa Cruz, Argentina. Relaciones de la Sociedad Argentina de Antropología X:271-292.

SCASSO, R. A. y E. O. EUGENIO. 1999. Estudio sedimentológico de la cueva Las Buitreras (Provincia de Santa Cruz, Argentina). Praehistoria 3:147-161.

SCASSO, R. A. y C. O. LIMARINO. 1997. Petrología y Diagénesis de Rocas Clásticas. Buenos Aires, Asociación Argentina de Sedimentología, Publicación Especial № 1.
SKEWES, M. A. 1978. Geología, petrología, quimismo y origen de los volcanes del área de Pali-Aike, Magallanes, Chile. Anales del Instituto de la Patagonia 9:95-10.

STEIN, J. K. 1990. Archaeological stratigraphy. En: Archaeological geology of North America. Editado por: N. P. Lasca y J. Donahue. Geological Society of America, Centennial Special Volume 4:513-523. 2001. Archaeological Sediments in Cultural Environments. En: Sediments in Archaeological Context. Editado por: J. K. Stein y W. R. Farrand, pp. 1-28. Salt Lake City, The University of Utah Press.

TSOAR, H. y J . T. MpLLER. 1986. The role of vegetation in the formation of linear sand dunes. En: Aeolian Geomorphology. Editado por: W. C. Nickling., pp. 75-95. Boston, Allen \& Unwin.

URIBE, P. y E. ZAMORA M. 1981. Origen y geomorfología de la Punta Dungeness, Patagonia. Anales del Instituto de la Patagonia 12:143-158.

VITA-FINZI, C. 1978. Archaeological Sites in their Setting. Londres, Thames and Hudson.

WATERS, M. R. 1992. Principles of G eoarchaeology: a North American Perspective. Tucson, The University of Arizona Press.

ZÁRATE, M. y A. PRIETO. 1994. Role of the Geological Sciences in the Archaeological Research of Buenos Aires Province, Argentina. Quaternary of South America and Antarctic Peninsula 10:311-320.

ZOLITSCHKA, B.; F. SCHÄBITZ; A. LÜCKE; M. WILLE; C. MAYR; C. OHLENDORF; F. ANSELMETTI; D. ARIZTEGUI; H. CORBELLA; B. ERCOLANO; $M$. FEY; T. HABERZETTL; N. MAIDANA; G. OLIVA; M. PÁEZ y G. SCHLESER. 2004. Climate Changes in Southern Patagonia (Santa Cruz, Argentina) Inferred From Lake Sediments: The Multi-Proxy Approach of SALSA. PAGES News 12 (2):9-11. 